\title{
Structural investigations of the ferredoxin and terminal oxygenase components of the biphenyl 2,3-dioxygenase from Sphingobium
} yanoikuyae B I

\author{
Daniel J Ferraro $^{\dagger 1}$, Eric N Brown ${ }^{\dagger 1}$, Chi-Li Yu ${ }^{2}$, Rebecca E Parales ${ }^{3}$, \\ David T Gibson ${ }^{2}$ and S Ramaswamy*1
}

\begin{abstract}
Address: ${ }^{1}$ Department of Biochemistry, University of Iowa Roy J. and Lucille A. Carver College of Medicine, 51 Newton Road, 4-611 BSB, Iowa City, Iowa, 52242, USA, 2Department of Microbiology, University of Iowa Roy J. and Lucille A. Carver College of Medicine, 51 Newton Road, 3 711 BSB, Iowa City, Iowa, 52242, USA and '3ection of Microbiology, University of California, Davis, 226 Briggs Hall, One Shields Avenue, Davis, CA 95616, USA

Email: Daniel J Ferraro - daniel-ferraro@uiowa.edu; Eric N Brown - eric-n-brown@uiowa.edu; Chi-Li Yu - chi-li-yu@uiowa.edu; Rebecca E Parales - reparales@ucdavis.edu; David T Gibson - david-gibson@uiowa.edu; S Ramaswamy* - s-ramaswamy@uiowa.edu * Corresponding author †Equal contributors
\end{abstract}

Published: 9 March 2007

BMC Structural Biology 2007, 7:10 doi:10.1 186/1472-6807-7-10

This article is available from: http://www.biomedcentral.com//472-6807/7//10

(c) 2007 Ferraro et al; licensee BioMed Central Ltd.

This is an Open Access article distributed under the terms of the Creative Commons Attribution License (http://creativecommons.org/licenses/by/2.0), which permits unrestricted use, distribution, and reproduction in any medium, provided the original work is properly cited.
Received: II October 2006

Accepted: 9 March 2007

\begin{abstract}
Background: The initial step involved in oxidative hydroxylation of monoaromatic and polyaromatic compounds by the microorganism Sphingobium yanoikuyae strain $\mathrm{BI}(\mathrm{BI})$, previously known as Sphingomonas yanoikuyae strain $\mathrm{BI}$ and Beijerinckia sp. strain $\mathrm{BI}$, is performed by a set of multiple terminal Rieske non-heme iron oxygenases. These enzymes share a single electron donor system consisting of a reductase and a ferredoxin $\left(B P D O-\mathrm{F}_{\mathrm{BI}}\right)$. One of the terminal Rieske oxygenases, biphenyl 2,3-dioxygenase $\left(B P D O-O_{B I}\right)$, is responsible for $\mathrm{BI}$ 's ability to dihydroxylate large aromatic compounds, such as chrysene and benzo[a]pyrene.
\end{abstract}

Results: In this study, crystal structures of $B P D O-O_{B I}$ in both native and biphenyl bound forms are described. Sequence and structural comparisons to other Rieske oxygenases show this enzyme to be most similar, with $43.5 \%$ sequence identity, to naphthalene dioxygenase from Pseudomonas sp. strain NCIB 98I6-4. While structurally similar to naphthalene I,2-dioxygenase, the active site entrance is significantly larger than the entrance for naphthalene 1,2-dioxygenase. Differences in active site residues also allow the binding of large aromatic substrates. There are no major structural changes observed upon binding of the substrate. BPDO- $\mathrm{F}_{\mathrm{B} \mid}$ has large sequence identity to other bacterial Rieske ferredoxins whose structures are known and demonstrates a high structural homology; however, differences in side chain composition and conformation around the Rieske cluster binding site are noted.

Conclusion: This is the first structure of a Rieske oxygenase that oxidizes substrates with five aromatic rings to be reported. This ability to catalyze the oxidation of larger substrates is a result of both a larger entrance to the active site as well as the ability of the active site to accommodate larger substrates. While the biphenyl ferredoxin is structurally similar to other Rieske ferredoxins, there are distinct changes in the amino acids near the iron-sulfur cluster. Because this ferredoxin is used by multiple oxygenases present in the $\mathrm{BI}$ organism, this ferredoxin-oxygenase system provides the structural platform to dissect the balance between promiscuity and selectivity in protein-protein electron transport systems. 


\section{Background}

Sphingobium yanoikuyae B1 (B1), previously known as Sphingomonas yanoikuyae B1 and Beijerinckia sp. strain B1 [1], was isolated by virtue of its ability to use biphenyl as its sole source of carbon and energy for growth [2]. B1 is capable of using naphthalene, phenanthrene, anthracene, toluene, $m$ - and $p$-xylene as sole sources of carbon and energy [3]. Other compounds are also oxidized by this microorganism and many of these are converted to cisdihydrodiols. B1 remains one of the only known microbes, along with Mycobacterium vanbaalenii PYR1 [4] and Sphingomonas sp. strain CHY-1 [5-7], able to oxidize large aromatic hydrocarbons such as benzo[a]pyrene, benzo[a]anthracene and chrysene [8] to cis-dihydrodiols.

In the B1 genome, at least six sets of putative oxygenase genes are present [9] and are all believed to share a common electron donor system [10]. The genes bphA1A2f, which encode $\mathrm{BPDO}-\mathrm{O}_{\mathrm{B} 1}$, have been sequenced and found to encode a Rieske oxygenase (RO) [11-13] related to naphthalene and biphenyl dioxygenases [14]. BPDO$\mathrm{O}_{\mathrm{B} 1}$ is responsible for the oxidation of large aromatic compounds, such as benzo[a]pyrene, by B1. Structural information [15-17] and molecular modeling [18] have been used to determine features important for substrate specificity in other biphenyl oxidizing oxygenases; however, most of the effort has been targeted at understanding how biphenyl dioxygenases catalyze the degradation of polychlorinated biphenyls (reviewed in [19-22]). Previous structural studies of several ROs provide insight into common features of how the terminal component of the RO systems are organized and how substrate interacts with the enzyme to form the hydroxylated product [23]. To date, structures of enzymes that catalyze cis-dihydroxylation of aromatic substrates with more than three rings have not been reported.

Rieske oxygenase systems have multiple components whose function is to transfer electrons from NAD $(\mathrm{P}) \mathrm{H}$ to active molecular oxygen and ultimately oxidize aromatic hydrocarbon substrates [23]. A single reductase for the multiple Rieske oxygenases is present in the $\mathrm{B} 1$ genome [10]. This reductase passes one electron at a time from $\mathrm{NAD}(\mathrm{P}) \mathrm{H}$ to the Rieske ferredoxin, BPDO- $\mathrm{F}_{\mathrm{B} 1}$, which in turn passes the electron on to the dioxygenase enzyme [24]. The terminal oxygenase component is responsible for catalyzing the addition of molecular oxygen to the aromatic substrate. This occurs at the mononuclear iron, contained in a large, primarily hydrophobic active site. The residues that form the active site have been shown to control substrate specificity.

Here we report the structures of BPDO- $\mathrm{F}_{\mathrm{B} 1}$ and BPDO$\mathrm{O}_{\mathrm{B} 1}$. The structure of $\mathrm{BPDO}-\mathrm{F}_{\mathrm{B} 1}$ shows similarities and important differences compared to other known Rieske dioxygenase ferredoxins. Structures of BPDO-O ${ }_{\mathrm{B} 1}$, in both the native form and bound to biphenyl, are presented. These structures demonstrate how BPDO-O ${ }_{\mathrm{B} 1}$ binds substrate in the active site. We also discuss the similarities and differences of this terminal oxygenase to other RO terminal oxygenase structures that have been previously determined and how these differences play a role in substrate specificity and regio- and stereoselectivity of product formation.

\section{Results \& discussion}

\section{Ferredoxin structure determination}

The asymmetric unit contains two copies of the BPDO- $\mathrm{F}_{\mathrm{B} 1}$ molecule. The final model contains residues 3 - 104 in chains $\mathrm{A}$ and $\mathrm{B}$. The structure has been refined to a resolution of $1.9 \AA$ with a final $\mathrm{R}_{\text {factor }}$ of $19.3 \%$ and an $\mathrm{R}_{\text {free }}$ of $24.0 \%$. The first two N-terminal and last three C-terminal residues could not be modeled into the electron density. The superposition of all C $\alpha$ atoms in both chains using Lsqman [25] had an RMSD of $0.40 \AA$ A. Residues Lys-25, Pro-104, and Glu-95 through Gly-97 had the largest deviations between chains A and B. The surface loop containing Lys-25 and Met-26 had little to no density for their side chains, Pro-104 is the last residue modeled, while Asp-96 assumes two conformations in chain B. The Rieske [2Fe-2S] cluster had isotropic displacement factors of 19.6 and $18.5 \AA^{2}$ for chains $\mathrm{A}$ and $\mathrm{B}$ respectively. Crystallographic statistics are reported in Table 1.

\section{Oxygenase structure determination}

The asymmetric unit contains the entire BPDO-O ${ }_{\mathrm{B} 1} \alpha_{3} \beta_{3}$ hexamer and residues $6-454$ of the $\alpha$ subunits and residues 5 - 174 of the $\beta$ subunits were modeled into the electron density. The structure has been refined to a resolution of $1.7 \AA$ with a final $\mathrm{R}_{\text {factor }}$ of $18.8 \%$ and an $\mathrm{R}_{\text {free }}$ of 22.9 $\%$. The loop region located at the entrance of the $\alpha$ subunit active site is disordered, with higher than average $\mathrm{B}$ factors and low side-chain electron density. This region spanned from residues 220 - 240 with residues $235-239$ being the most disordered. Corresponding regions in other ROs are also disordered [15,26-30]. Lsqkab [25] was used to determine the superposition RMSDs of the three $\alpha$ and $\beta$ subunits in the asymmetric unit. A few regions in the $\alpha$ subunit, residues $108-123$ and $411-434$, and in the $\beta$ subunit, residues $77-85$ and $139-148$, had higher than average RMSDs when compared; however, electron density clearly defined the coordinates of these residues. Crystallographic statistics are reported in Table 1.

\section{Structure of the substrate-free oxygenase enzyme}

The three copies of the $\alpha$ and $\beta$ subunits form an $\alpha_{3} \beta_{3}$ quaternary structure similar to the quaternary structure observed in all known RO structures. The hexamer forms a mushroom-shaped structure, illustrated in Figure 1, where the three $\alpha$ subunits form the cap and the three $\beta$ 
Table I: Summary of crystallographic data and refinement statistics

\begin{tabular}{|c|c|c|c|}
\hline Crystal & Ferredoxin (2I7F) & Oxygenase (native) (2GBW) & Oxygenase (biphenyl bound) (2GBX) \\
\hline Space group & $\mathrm{P}_{5} 22$ & $P 3,21$ & $\mathrm{P} 3,2 \mathrm{I}$ \\
\hline \multicolumn{4}{|l|}{ Cell parameters } \\
\hline$a=b(\AA)$ & 62.064 & 134.96 & 134.43 \\
\hline$c(\AA)$ & 238.436 & 219.89 & 220.53 \\
\hline Resolution $(\AA)^{\prime}$ & $9.49-1.90 \AA(1.96-1.90 \AA)$ & $19.80-1.70 \AA(1.76-1.70 \AA)$ & $43.15-2.75(2.85-2.75)$ \\
\hline \multicolumn{4}{|l|}{ Data collection } \\
\hline X-ray source & NSLS X6A & IMCA-CAT I7-ID & IMCA-CAT I7-ID \\
\hline Wavelength $(\AA ̊)$ & 1.03320 & $1.00000 \AA$ & $1.00000 \AA$ \\
\hline Total observations & 108720 & 1083097 & 343108 \\
\hline Unique observations & 20866 & 241600 & 56040 \\
\hline Completeness (\%)। & $93.7 \%$ (65.2 \%) & $95.3 \%(98.1 \%)$ & $92.6 \%(99.7 \%)$ \\
\hline$(I) / \sigma(I) I$ & $8.2(2.9)$ & $8.2(2.9)$ & $9.6(3.7)$ \\
\hline Multiplicity! & $5.21(3.46)$ & $4.48(4.10)$ & $6.12(7.14)$ \\
\hline $\begin{array}{l}\mathrm{R}_{\text {sym }} 1,2 \\
\text { Crystallographic refin }\end{array}$ & $0.121(0.417)$ & $0.083(0.394)$ & $0.104(0.409)$ \\
\hline $\begin{array}{l}R_{\text {factor }} / R_{\text {free }}(\%)^{3} \\
\text { RMSD from ideality }\end{array}$ & $19.1 / 20.3$ & $18.8 / 22.9$ & $22.8 / 26.9$ \\
\hline Bond lengths $(\AA)$ & $0.017 \AA$ & $0.017 \AA$ & $0.006 \AA$ \\
\hline Bond angles (deg) & $1.925^{\circ}$ & $1.616^{\circ}$ & $0.880^{\circ}$ \\
\hline
\end{tabular}

I Outer shell values are in parentheses.

${ }^{2} R_{\text {sym }}=\frac{\sum_{h k l} \sum_{i}\left|I_{i}(h k l)-I(h k l)\right|}{\sum_{h k l} \sum_{i}\left|I_{i}(h k l)\right|}$, where $\mathrm{I}_{\mathrm{i}}(\mathrm{hkl})$ is the ith measurement of reflection hkl and l(hkl) is the average for that reflection.

${ }^{3} R_{\text {factor }}=\frac{\sum_{h k l}|| F_{o b s}|-k| F_{\text {calc }}||}{\sum_{h k l}\left|F_{o b s}\right|}$, where $\mathrm{F}_{\mathrm{obs}}$ and $\mathrm{F}_{\text {calc }}$ are the observed and calculated structure factors, respectively. $\mathrm{R}_{\text {free }}$ is the same, but

for a test set of reflections not used in refinement.

subunits form the stem. The hexamer structure is believed to be the active biological unit, similar to other known ROs.

The $\alpha$ subunit consists of 454 residues, which form two domains. The N-terminal portion consists of a Rieske [2Fe-2S] iron-sulfur cluster domain, defined by residues $40-140$. The Rieske domain consists of $\beta$ strands and loops, forming an ISP domain fold [31]. Four residues, two histidines and two cysteins, in the $\alpha$ subunit coordinate the Rieske non-heme iron cluster [2Fe-2S]. His- 82 and His-103 coordinate one iron, while Cys- 80 and Cys100 coordinate the other. The C-terminal domain is a mix of helices and strands forming a TBP-like or helix-grip fold and is a member of the Bet v1-like superfamily [31]. The structural conservation suggests that the intraprotein electron transport in BPDO- $\mathrm{O}_{\mathrm{B} 1}$ is similar to the system described for $\mathrm{NDO}_{-} \mathrm{O}_{9816-4}$ and benzoate dioxygenase [3237].

The mononuclear iron is coordinated by two histidines, His-207 and His-212, and one aspartate, Asp-360, at the rear of the active site. This iron has been shown to bind water(s) or dioxygen in other structures. In BPDO- $\mathrm{O}_{\mathrm{B} 1}$, a clear bimodal electron density distribution was not observed, but instead an egg-shaped electron density above the mononuclear iron was present (Figure 2). When a single water/hydroxide molecule was modeled in this position, it resulted in residual positive density on the Fo-Fc electron density maps. Residual positive electron density was not observed on the Fo-Fc electron density maps when modeling molecular oxygen as the fourth iron ligand; however, refinement with relaxed restraints (refinement restraints allowing the oxygen-oxygen bond an RMSD of $0.3 \AA$ ) placed the oxygen-oxygen bond distance at $0.8-1.1 \AA$ in the three subunits. This is slightly shorter than the average distance of $1.21 \AA$ between two oxygen atoms in $\mathrm{O}_{2}$. B-factors for the refined oxygen molecule also suggested that it was less than fully occupied. The final model has both molecular oxygen and water bound to the iron in partially occupied states (Figure 2). In previous studies, both dioxygen species $[15,27,38,39]$ and water $[16,26,28,29,39-42]$ have been observed as ligands in RO crystals grown in atmospheric conditions. The 

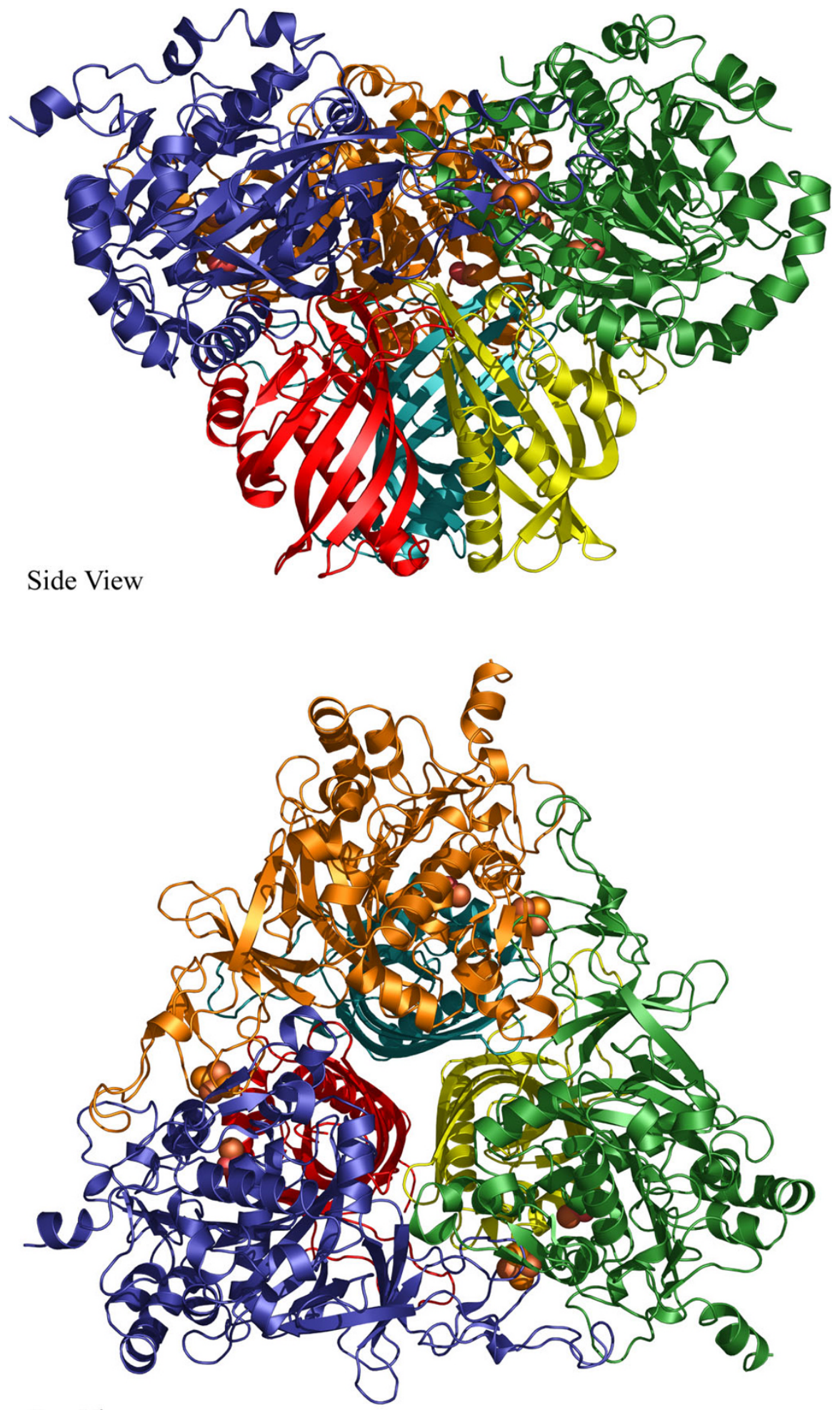

Top View

Figure I

Top and side view of the BPDO-O ${ }_{B}$ hexamer. The structure of biphenyl 2,3-dioxygenase is a mushroom-shaped $\alpha_{3} \beta_{3}$ hexamer. This quaternary structure is typical of $\alpha \beta$ Rieske oxygenases. This structure allows a mononuclear iron from one $\alpha$ subunit to come within $\sim 15 \AA$ of a Rieske cluster from a neighboring subunit, allowing electron transfer to take place. 
$\mathrm{BPDO}-\mathrm{O}_{\mathrm{B} 1}$ crystals were grown in atmospheric conditions, therefore molecular oxygen or water could constitute the fourth ligand on the mononuclear iron.

The $\beta$ subunit of $\mathrm{BPDO}-\mathrm{O}_{\mathrm{B} 1}$ has a Cystatin-like protein fold and belongs to the protein superfamily of NTF2-like proteins [31]. The function of the $\beta$ subunits of ROs is not well understood and reports vary as to whether or not mutations in the $\beta$ subunit of ROs can influence regioselectivity of product formation (reviewed in [43]). In the case of $\mathrm{BPDO}-\mathrm{O}_{\mathrm{B} 1}$, the $\beta$ subunit is not directly involved in creating the topology of the active site; however, the mononuclear iron is within $11 \AA$ of the $\alpha-\beta$ subunit interface. This distance may allow select $\beta$-subunit side chains to indirectly affect the topology of the active site by interacting with residues that directly form the active site.

\section{Structure of the biphenyl bound oxygenase enzyme}

B1 has been shown to catalyze the dihydroxylation of biphenyl at positions 2 and 3 of the carbon ring [2,44] and recent studies have confirmed that $\mathrm{BPDO}-\mathrm{O}_{\mathrm{B} 1}$ is responsible for this activity [45]. Previous structural investigations of ROs have demonstrated that substrate bound in the active site is oriented such that the carbon(s) oxidized in the dihydroxylation reaction is (are) closest to the mononuclear iron $[16,26,27,30,40,42,46]$. This trend is also seen in the structure of BPDO-O $\mathrm{B}_{\mathrm{B} 1}$ bound to biphenyl. The 2 and 3 carbons of biphenyl are positioned closest to the iron, with a water/hydroxide molecule bound to the iron positioned between the substrate and the iron (Figure 3). Crystals were grown and biphenyl was added in the presence of atmospheric oxygen. The enzyme was oxidized and no electron source was added; therefore,

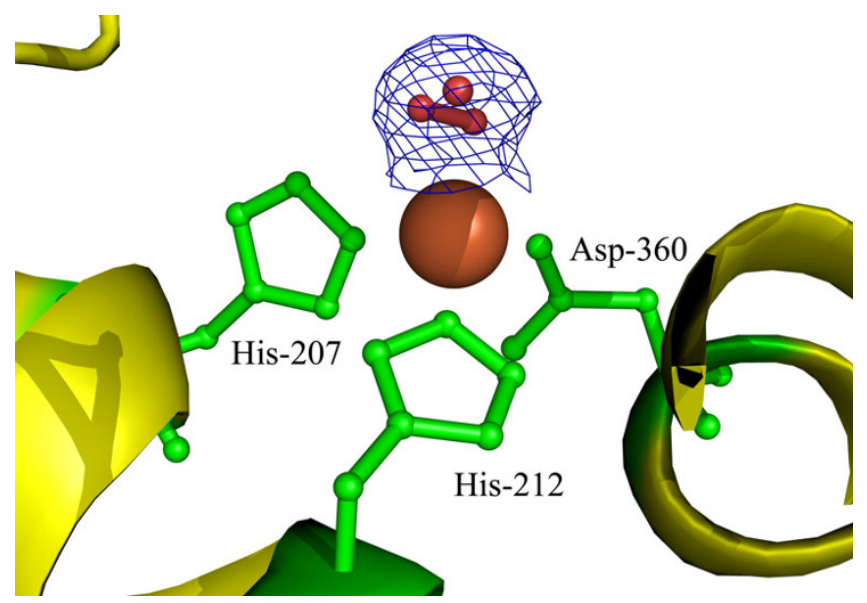

Figure 2

Mononuclear iron bound to oxygen and water. Active site of BPDO-O $\mathrm{O}_{\mathrm{BI}}$ showing the dioxygen molecule and water molecule modeled. The dioxygen molecule is shown as a ball and stick molecule, while a sphere represents the water molecule. The mesh is I.0 $\sigma$ 2Fo-Fc electron density. catalysis did not occur. We are unable to determine whether the iron is coordinated to a water molecule (hydroxide ion) or an oxygen molecule at this resolution. No significant changes in the active site main chain were observed near the mononuclear iron compared to the native structure. However, small changes in the mainchain and side-chain positions of the distal portion of the active site were observed. The largest changes were seen in the loop regions that cover the entrance to the active site. The loop main-chain was pushed slightly away ( $0.2-0.3$ $\AA$ ) from the substrate in the complex structure, while the main-chain proximal to the mononuclear iron remained static.

\section{Comparison of BPDO- $F_{B I}$ to other Rieske oxygenase ferredoxins}

The structure of the biphenyl dioxygenase system's ferredoxin component, BPDO- $\mathrm{F}_{\mathrm{B} 1}$, is the fourth Rieske oxygenase ferredoxin structure to be determined and shares significant sequence and structural homology with these proteins (Table 2). BPDO- $\mathrm{F}_{\mathrm{B} 1}$ has structural features similar to other ferredoxins including three stacked beta sheets and a solvent exposed Rieske cluster (Figure 4) [47]. The protein fold surrounding the Rieske cluster is similar in all Rieske ferredoxins, including the high-potential Rieske ferredoxins found in respiratory electron transport chains such as the $\mathrm{bc}_{1}$ complex [48] and the Rieske clusters found in dioxygenase enzymes such as $\mathrm{BPDO}-\mathrm{O}_{\mathrm{B} 1}$.

In addition to the conserved CXH-CXXH motif present in all Rieske ferredoxins, there are two additional conserved residues, Phe-71 and Pro-82, in the dioxygenase ferredoxins $[47,49,50]$. The phenylalanine is part of the small ferredoxin core near the Rieske cluster. The neighboring side-chains include Thr-46, Leu-52 and Ile-87. These residues are highly conserved with Thr-46 most commonly being a serine or a threonine, Leu-52 existing almost exclusively as a leucine, and Ile- 87 being the most varied with leucine as the most common substitution (Table 3 ). The conserved proline is located at a hairpin turn at the apex of the ferredoxin and has previously been classified as part of a polyproline loop in Rieske ferredoxins (Figure 5). Unlike the biphenyl ferredoxin from LB400, which has three consecutive prolines, this ferredoxin has only a single proline in the loop.

The reduction potential of the Rieske cluster in bacterial dioxygenase systems is expected to be approximately -150 $\mathrm{mV}$, similar to that found in BPDO-F ${ }_{\mathrm{LB} 400}$ [47] and NDO$\mathrm{F}_{9816-4}$ (Lindsay Eltis, personal communicaton). It is believed that the local electrostatic environment, created by charged and hydrogen bonded residues near the cluster, differentiates the reduction potential of the cluster from homologous structures. Thus the low potential oxygenase ferredoxins, with negative reduction potentials, have an electrostatic environment that is more negative 
than the mitochondrial Rieske ferredoxins, with positive reduction potentials. BPDO- $\mathrm{F}_{\mathrm{B} 1}$ is the ideal protein for exploring these effects; unlike the other Rieske oxygenase ferredoxins, this protein contains a residue which hydrogen bonds to the cluster through the side-chain (Figure 6), as opposed to through the main-chain as present in other ferredoxins. Thus substitution of Cys-83 with alanine, valine, or serine, can probe the effect of local charge and hydrogen bonding on the reduction potential. Interestingly, the conserved Phe-71 in dioxygenase Rieske ferredoxins is exclusively a tyrosine in the Rieske ferredoxins found in mitochondrial and chloroplast electron transport chains. The increased polarity or hydrogen bonding ability of the tyrosine may assist in raising the reduction potential of these ferredoxins. This provides a second rational target for mutational analysis.

\section{Comparison of BPDO-O ${ }_{B I}$ to other Rieske oxygenases}

The X-ray diffraction structural model shows that BPDO$\mathrm{O}_{\mathrm{B} 1}$ is structurally similar to other known ROs, as predicted by sequence analysis. Structure and sequence alignment confirm that NDO- $\mathrm{O}_{9816-4}$ is the most structurally similar, with most of the variation in the $\alpha$ subunit around the active site. Table 2 gives information on sequence and structural similarity between BPDO-O ${ }_{\mathrm{B} 1}$ and other ROs. Of the 21 residues that form the active site, only 6 differ from NDO-O ${ }_{9816-4}$. Thr-308 in BPDO-O ${ }_{\mathrm{B} 1}$, analogous to Ser-310 in NDO-O ${ }_{9816-4}$, is positioned at the entrance to the active site. Thr-308 seems to push residue Leu-260 toward the entrance of the active site compared to the position of Val-260 in NDO-O ${ }_{9816-4}$. This change results in an indentation in the wall at the far side of the active site. Leu-356 in BPDO- $\mathrm{O}_{\mathrm{B} 1}$, analogous to Trp-358 in NDO- ${ }_{9816-4}$, also contributes to this relative indentation in the active site wall. Residue Phe-224 in NDO$\mathrm{O}_{9816-4}$ is also in this bulge region and is analogous to Leu223 in BPDO- $\mathrm{O}_{\mathrm{B} 1}$. Leu-226 is conserved between BPDO$\mathrm{O}_{\mathrm{B} 1}$ and NDO- $\mathrm{O}_{9816-4}$, but the side-chain positions differ. These mutations and side-chain rotamer conformations effectively make a hydrophobic indentation in the wall of the active site, both changing the shape and increasing the volume of the active site compared to $\mathrm{NDO}-\mathrm{O}_{9816-4}$. A similar indentation is present in the structure of BPDO$\mathrm{O}_{\mathrm{RHA} 1}[16]$ (Figure 7). In both BPDO- $\mathrm{O}_{\mathrm{RHA1}}$ and BPDO$\mathrm{O}_{\mathrm{B} 1}$, the phenyl ring of biphenyl distal to the mononuclear iron is in this portion of the active site. By situating the distal ring in this location, the enzyme is able to position the 2 and 3 carbons to be directly facing the mononuclear iron. In NDO-O ${ }_{9816}$, the side-chain of Trp-358 occupies part of this indentation, which would cause the biphenyl substrate to rotate slightly, relative to the mononuclear iron. This rotation would move the 2 carbon farther away from the iron and the 4 carbon closer. This would also explain the differences in the regioselectivity of enzymes, where BPDO- $\mathrm{O}_{\mathrm{B} 1}$ and BPDO-O $\mathrm{RHA1}_{\text {1 }}$ produce the cis-2,3-biphenyldiol exclusively, while $\mathrm{NDO}-\mathrm{O}_{9816-4}$ produces a mixture of the cis-2,3- and cis-3,4-biphenyldiol [51].

The BPDO- $\mathrm{O}_{\mathrm{RHA1}}$ (PDB entry $1 \mathrm{ULI}$ ) active site has a significantly smaller volume, $\sim 27 \AA^{3}$, than BPDO- $\mathrm{B}_{\mathrm{B} 1}, \sim 43 \AA^{3}$. This is due to bulkier side-chains in BPDO- $\mathrm{O}_{\mathrm{RHAl}}$ and var-
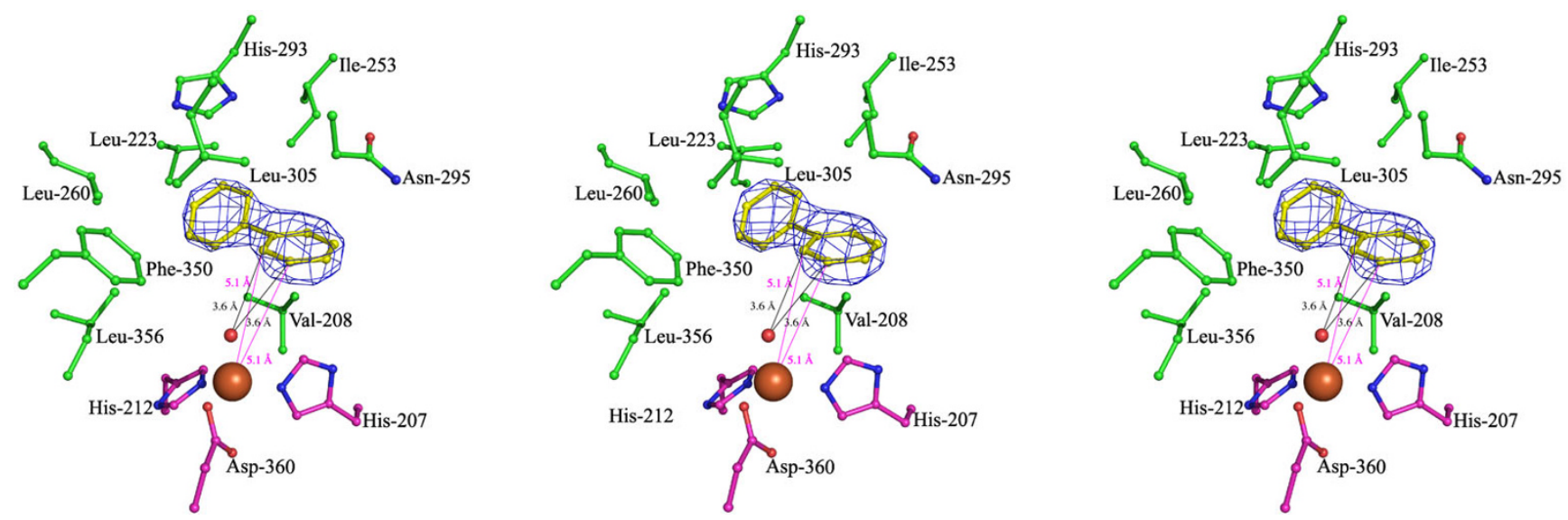

Figure 3

BPDO-O ${ }_{B}$ bound to biphenyl. Stereo image of the active site of BPDO-O $\mathrm{B}_{\mathrm{B}}$ with biphenyl bound. The biphenyl molecule is shown in yellow. A I.0 $\sigma 2$ Fo-Fc electron density map calculated without biphenyl present (unbiased) is shown in blue mesh for the biphenyl ligand. The residues that coordinate the mononuclear iron are shown in red, while the residues that form the active site pocket are shown in green. Black lines show distances between the biphenyl carbons and the mononuclear iron and red lines show distances between the biphenyl carbons and the water/hydroxide bound to the mononuclear iron. Left and center images are wall-eyed stereo, center and right images are cross-eyed stereo. 


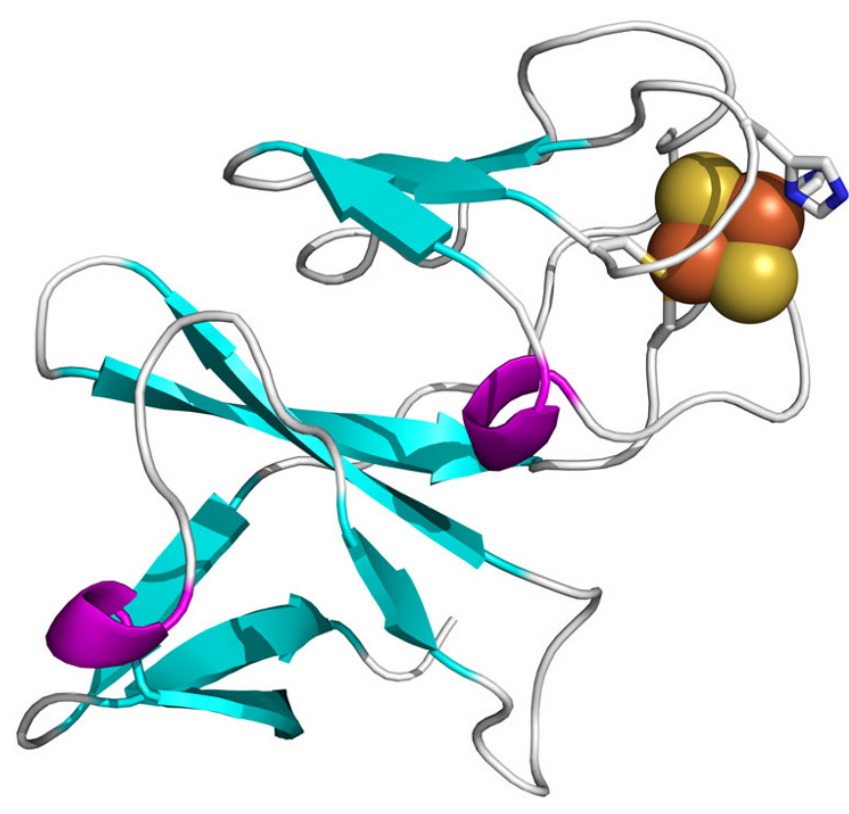

Figure 4

Ribbon diagram of BPDO-F $F_{B I}$ showing the location of the Rieske iron-sulfur cluster. The ribbon diagram shows the conserved Rieske binding domain of the ferredoxin, where the Rieske cluster is positioned near the surface of the protein. The Rieske cluster is shown as spheres, where iron is orange and sulfur is yellow. The residues that directly interact with the Rieske cluster are shown as sticks. Beta sheets are shown in blue and alpha helices are shown in purple.

iability in the loop positions at the active site entrance. Comparing the ligand bound structures, biphenyl carbons 2 and 3 are closer to the mononuclear iron in BPDO$\mathrm{O}_{\mathrm{RHA} 1}, 4.3$ and $4.6 \AA$ respectively, as compared to BPDO$\mathrm{O}_{\mathrm{B} 1}$ which has an average distance of approximately $5.0 \AA$ for both the 2 and 3 carbons in the three subunits. However, in both BPDO-O $\mathrm{RHA}_{\mathrm{R} 1}$ and $\mathrm{BPDO}-\mathrm{O}_{\mathrm{B} 1}$, the distances between the biphenyl and the iron-bound water are similar. The closer position in BPDO-O ${ }_{\mathrm{RHA} 1}$ is mediated by an interaction with Met-222, which is not present in BPDO$\mathrm{O}_{\mathrm{B} 1}$. The glycine (Gly-205) present in the structurally analogous position leaves room for the ligand to move slightly further from the iron. The lack of large side-chain rearrangement upon substrate binding is similar to results seen in NDO-O ${ }_{9816-4}[27,40]$ and BPDO-O ${ }_{\text {RHA1 }}[16]$. The loop covering the active site entrance of $\mathrm{BPDO}-\mathrm{O}_{\mathrm{B} 1}$ shifts upon binding of biphenyl. While large changes in this loop are not seen in the structures of NDO-O ${ }_{9816-4}$, this loop is believed to be flexible in NDO-O ${ }_{9816-4}[27,40]$. BPDO-O ${ }_{\text {RHA1 }}$ does show significant movement of residues 271 - 276 shifting $1-2 \AA$ toward the active site, with the side-chain Leu-274 forming van der Waals interactions with the ligand [16]. Loops covering the active site in the $\alpha_{3}$ Rieske monooxygenase 2-oxoquinoline 8-monooxygenase also demonstrate changes upon substrate binding [30]. This loop motion observed in the $\mathrm{BPDO}-\mathrm{O}_{\mathrm{B} 1}$ and other RO structures allows the active site to "breathe" to accommodate ligands and may be one of the key features that allows this class of enzymes to perform catalysis on diverse sets of substrates with respect to overall size and shape.

\section{Role of oxygenase active site entrance}

Evidence for large aromatic compound dihydroxylation by NDO-O ${ }_{9816-4}$ has not been observed in the past. While the overall active site volumes are relatively similar between $\mathrm{NDO}-\mathrm{O}_{9816-4}$ and $\mathrm{BPDO}-\mathrm{O}_{\mathrm{B} 1}$, the active site entrance of $\mathrm{BPDO}-\mathrm{O}_{\mathrm{B} 1}$ is larger. Phe-235 is positioned further away from the active site in $\mathrm{BPDO}-\mathrm{O}_{\mathrm{B} 1}$ compared to the analogous residue in $\mathrm{NDO}^{-\mathrm{O}_{9816-4}}$. This, along with the decreased side-chain bulk at Leu-223, compared to NDO-O ${ }_{9816-4}$, effectively increases the size of the active site entrance in BPDO-O $\mathrm{B}_{\mathrm{B} 1}$. Figure 8 and Additional file 1 demonstrate the differences in the active site entrance between $\mathrm{BPDO}-\mathrm{O}_{\mathrm{B} 1}$ and $\mathrm{NDO}-\mathrm{O}_{9816-4}$. The entrance to $\mathrm{RO}$ active sites is similar to an inverted funnel, with a small aperture leading to a large vestibule. Based on structural comparison, we propose that the shape and size of the active site entrance may keep larger substrates out of the NDO-O ${ }_{9816-4}$ active site even though there would be enough space inside the pocket to accommodate the ligand. Drawing from that comparison, we also believe that the active site entrance could influence the rates of product turnover by BPDO-O ${ }_{\mathrm{B} 1}$ with respect to large compounds, such as benzo[ $a]$ pyrene and benzo[a]anthracene. While studies to determine rates of product formation by BPDO-O ${ }_{\mathrm{B} 1}$ have not been performed to date, it has been shown that biotransformation of large compounds, such as benzo[a]pyrene and benzo[ $a]$ anthracene are much less efficient than those for smaller compounds such as naphthalene, and biphenyl [2,3,8,11,52]

\section{Conclusion}

Crystal structures of $\mathrm{BPDO}-\mathrm{F}_{\mathrm{B} 1}$ and $\mathrm{BPDO}-\mathrm{O}_{\mathrm{B} 1}$ from Sphingobium yanoikuyae strain $\mathrm{B} 1$ are presented and demonstrate strong structural conservation with other RO ferredoxin and oxygenase components. The structures reported here provide a rational basis for the ability of

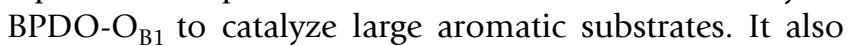
provides a framework to interpret the product regioselectivity of $\mathrm{BPDO}-\mathrm{O}_{\mathrm{B} 1}$ and the differences in product regioselectivity compared to other ROs. While the Rieske ferredoxin structure is very similar to other Rieske ferredoxins, the differences in amino acid composition near the cluster in $\mathrm{BPDO}-\mathrm{F}_{\mathrm{B} 1}$ provide a unique opportunity among the Rieske oxygenase ferredoxins to examine the effect of cluster environment and hydrogen bonding on reduction potential. 
Table 2: Sequence and structural statistics for various Rieske oxygenases compared to biphenyl 2,3-dioxygenase

\begin{tabular}{|c|c|c|c|}
\hline Ferredoxin (PDB ID) & $\operatorname{RMSD}(\mathbf{C} \alpha)$ & Sequence identity & Sequence similarity \\
\hline BPDO-F ${ }_{\mathrm{LB} 400}(\mathrm{IFQT})$ & $1.017(97)$ & $36.6 \%$ & $56.4 \%$ \\
\hline T4MOC-F (ISJG) & $1.697(93)$ & $24.1 \%$ & $52.7 \%$ \\
\hline CARDO-F $\mathrm{CAIO}$ (IVCK) & $1.312(98)$ & $36.3 \%$ & $60.8 \%$ \\
\hline $\begin{array}{l}\text { Terminal oxygenase } \alpha \\
\text { Subunit (PDB ID) }\end{array}$ & $\operatorname{RMSD}(\mathbf{C} \alpha)$ & Sequence identity & Sequence similarity \\
\hline NDO-O ${ }_{9816-4}($ INDO) & $1.24(420)$ & $43.5 \%$ & $62.0 \%$ \\
\hline NBDO-O ${ }_{J 5765}(2 \mathrm{BMO})$ & $1.23(4 \mid 3)$ & $41.2 \%$ & $59.4 \%$ \\
\hline BPDO-O & $1.48(388)$ & $39.6 \%$ & $55.1 \%$ \\
\hline CDO-O IPOI (IWQL) & $1.50(377)$ & $36.8 \%$ & $52.7 \%$ \\
\hline NDO-O ${ }_{12038}(2 \mathrm{BI} \mathrm{X})$ & $1.59(358)$ & $35.0 \%$ & $52.5 \%$ \\
\hline $\begin{array}{l}\text { Terminal oxygenase } \beta \text { Subunit } \\
\text { (PDB ID) }\end{array}$ & $\operatorname{RMSD}(\mathbf{C} \alpha)$ & Sequence identity & Sequence similarity \\
\hline NDO-O ${ }_{9816-4}($ INDO) & $1.19(156)$ & $28.1 \%$ & $46.0 \%$ \\
\hline NBDO-O $\mathrm{JS765}(2 \mathrm{BMO})$ & $1.19(160)$ & $29.5 \%$ & $47.0 \%$ \\
\hline BPDO-O RHAI $(I U L I)$ & $1.15(159)$ & $31.6 \%$ & $53.2 \%$ \\
\hline CDO-O ${ }_{I P O I}(I W Q L)$ & $1.17(16 \mathrm{I})$ & $31.8 \%$ & $48.6 \%$ \\
\hline NDO-O ${ }_{12038}(2 \mathrm{BIX})$ & $1.20(156)$ & $35.3 \%$ & $49.3 \%$ \\
\hline
\end{tabular}
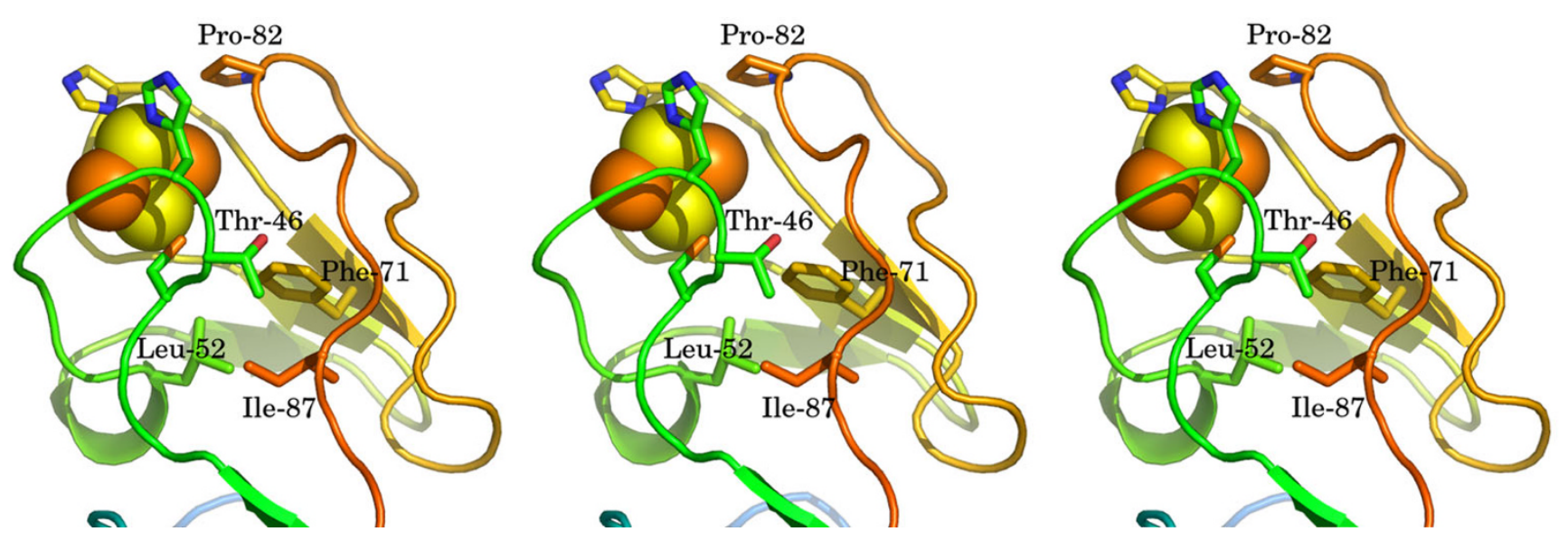

Figure 5

Stereo images showing the conserved residues near the Rieske cluster of BPDO-F $\mathbf{F}_{\mathbf{B} \mathbf{I}}$. The cartoon diagram shows that side chains of Thr-46, Leu-52, Phe-7I, and lle-87 form a highly conserved core among the Rieske oxygenase ferredoxins near the iron-sulfur cluster. The residues flanking Pro-82 are proline in BPDO-F $\mathrm{LB}_{400}$ and some high-potential Rieske ferredoxins, but are not proline in BPDO- $\mathrm{F}_{\mathrm{B} I}$. Left and center images are wall-eyed stereo, center and right images are cross-eyed stereo. 
Table 3: Structurally analogous residues near the iron-sulfur cluster in various Rieske dioxygenase ferredoxins

\begin{tabular}{|c|c|c|c|}
\hline BPDO-F $F_{B I}$ & BPDO-F ${ }_{L B 400}$ & T4MOC-F & CARDO-F ${ }_{\text {CAI } 0}$ \\
\hline \multicolumn{4}{|c|}{ Rieske cluster coordinating residues } \\
\hline CYS 45 & CYS 43 & CYS 45 & CYS 46 \\
\hline HIS 47 & HIS 45 & HIS 47 & HIS 48 \\
\hline CYS 64 & CYS 63 & CYS 64 & CYS 65 \\
\hline HIS 67 & HIS 66 & HIS 67 & HIS 68 \\
\hline \multicolumn{4}{|c|}{ Outer shell residues } \\
\hline ASN 43 & ASP 41 & ALA 43 & ASP 44 \\
\hline GLY 48 & GLY 46 & GLN 48 & GLY 49 \\
\hline ALA 50 & TRP 48 & & ALA 5I \\
\hline PHE 66 & LEU 65 & ALA 66 & PHE 67 \\
\hline GLY 69 & GLY 68 & TRP $49 *$ & GLY 69 \\
\hline ALA 80 & SER 79 & ASN 80 & SER $8 I$ \\
\hline CYS 83 & PRO 82 & & CYS 84 \\
\hline
\end{tabular}

In the structural superposition, residues marked with an asterisk were more than $3.0 \AA$ from the corresponding residue in $B P D O-\mathrm{O}_{\mathrm{B}}$.

\section{Methods}

Protein expression, purification and crystallization BPDO-O ${ }_{\mathrm{B} 1}$, bphA1fA2f $[11,14]$ and BPDO- $\mathrm{F}_{\mathrm{B} 1}$, bphA4 [10], were each cloned from B1 into the protein expression vectors pET101D (Invitrogen, Carlsbad, CA) and pT7-7, respectively, and expressed as described in Yu et al. [45]. Crystallization of the ferredoxin protein was performed using $33 \mathrm{mg} / \mathrm{mL}$ of BPDO- $\mathrm{F}_{\mathrm{B} 1}$ protein in a $50 \mathrm{mM}$ phosphate buffer, $\mathrm{pH} 6.8$, with $0.1 \mathrm{M}$ citric acid and $1.6 \mathrm{M}$ ammonium sulfate as precipitants. Crystallization of the oxygenase protein was performed using purified BPDO$\mathrm{O}_{\mathrm{B} 1}$ protein at $20 \mathrm{mg} / \mathrm{ml}$ in a $20 \mathrm{mM}$ potassium phosphate buffer, pH 6.8 [45]. Mineral oil was used as a cryoprotectant for the crystals.

Oxygenase crystals were also used for soaking experiments in an attempt to generate the BPDO- $\mathrm{O}_{\mathrm{B} 1}$ protein-biphenyl complex. Soaking experiments were based on similar experiments previously done with $\mathrm{NDO}-\mathrm{O}_{9816-4}$ to generate crystals of ligand-bound enzyme [27,38,40]. Crystals were moved to fresh drops containing reservoir buffer. Ethanol saturated with biphenyl was added to these drops. The crystals tolerated up to $5 \%$ ethanol in the drop. Crystals were allowed to soak for 3-5 days, then were removed from the drop and flash-cooled to $100 \mathrm{~K}$. Mineral oil was used as a cryoprotectant.

\section{Data collection, processing, structure solution and refinement}

X-ray diffraction data for BPDO- $\mathrm{F}_{\mathrm{B} 1}$ were collected on beamline X6A at Brookhaven National Laboratory and data for BPDO-O $\mathrm{B}_{\mathrm{B} 1}$ were collected on the IMCA-CAT beamline 17-ID at the Advanced Photon Source in Argonne National Laboratory. Crystallographic statistics are presented in Table 1. $\mathrm{d}^{*}$ TREK [53] was used to process the data for BPDO- $\mathrm{F}_{\mathrm{B} 1}$ to a resolution of $1.60 \AA$. Analyzing systematic absences, the space group was determined to be either $\mathrm{P}_{1} 22$ or $\mathrm{P}_{5} 22$. Molecular replacement using AMoRe [54] and a polyalanine model based on BPDO$\mathrm{F}_{\mathrm{LB} 400}$ (PDB entry 1FQT) produced a solution in space group $\mathrm{P}_{5} 22$. Model building using $\mathrm{O}$ [55] and Coot [56], density modification using $\mathrm{DM}$, and refinement using Refmac5 [57] from the CCP4-4.0 program suite were assisted by non-crystallographic symmetry between the two monomers in the asymmetric unit. These NCS restraints were loosened as refinement progressed. Cycles of Refmac5 with ARP/wARP [58,59] or the Coot find waters routines were used to identify solvent atoms. Asp96 in chain B was modeled as having two side chain conformations. A single round of TLS optimization was used at the end of refinement with each protein monomer acting as a TLS group.

Data collected from native $\mathrm{BPDO}-\mathrm{O}_{\mathrm{B} 1}$ crystals was processed using d*TREK [53] to a resolution of $1.70 \AA$. Analysis of systematic absences suggested that the space group was $P 3_{\mathrm{x}} 21$. Molecular replacement was performed using a polyalanine model based on NDO-O ${ }_{9816-4}(\mathrm{PDB}$ entry 1NDO) [28]. Molecular replacement using AMoRe [54] gave a clear solution in the space group $P 3_{1} 21$. Initial refinement of the polyalanine model with the program Refmac5 [57] of the CCP4-5.0.2 [60] suite of programs yielded good starting electron densities. The molecular visualization program $\mathrm{O}$ [55] was used for model building. After the bulk of the structure was modeled, refinement was continued with Refmac5 without NCS restraints. Solvent molecules were found using the program Arp/Warp $[58,59]$ and multiple side-chain confor- 


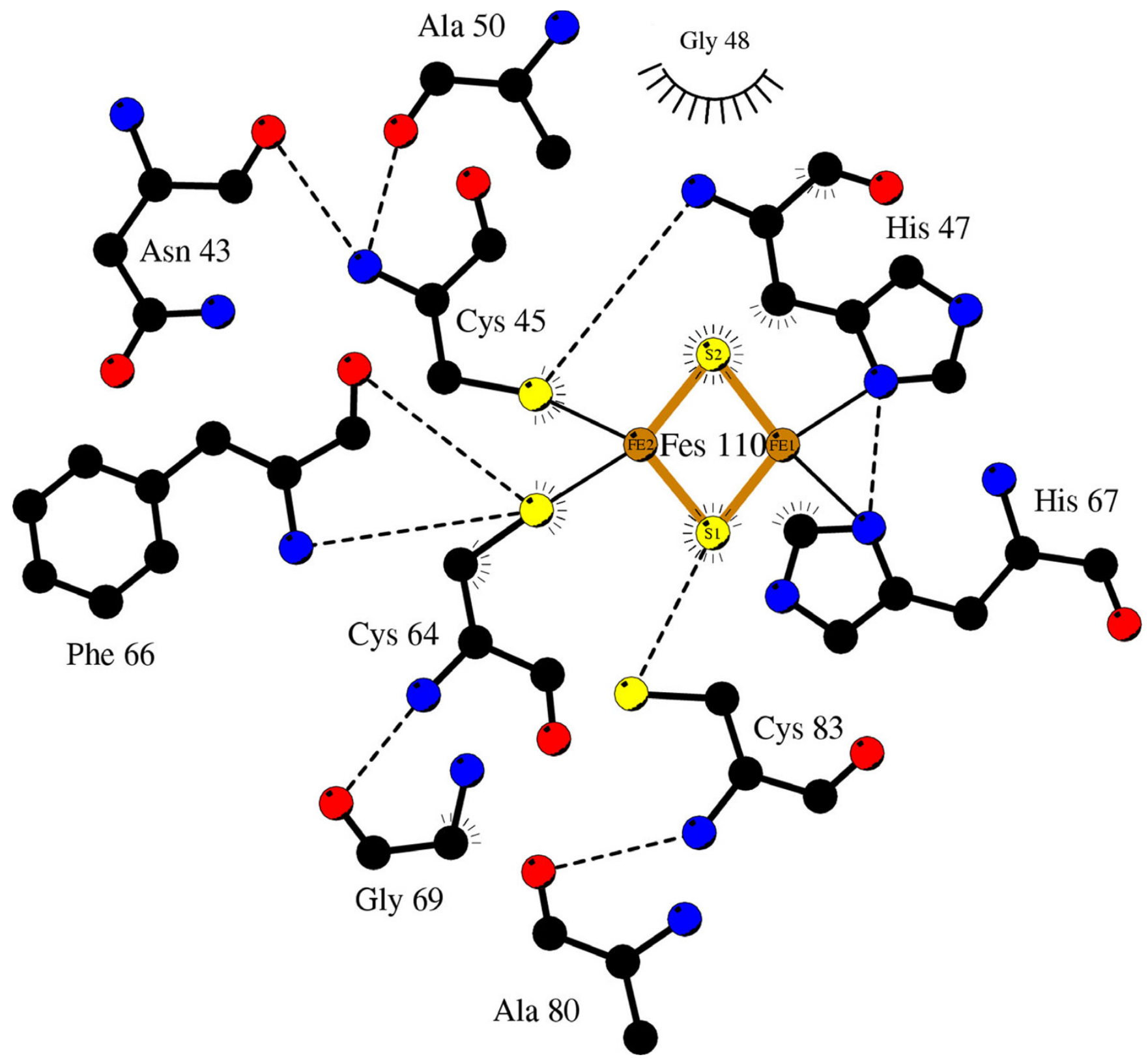

Figure 6

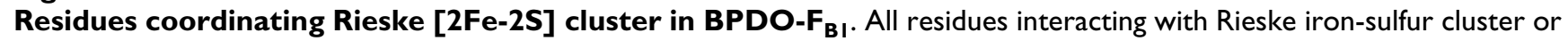
its ligands. Hydrogen bonds are displayed in dashed lines. Gly-48 interacts with His-47 and Ala-50 via hydrophobic interactions. Note the interaction between the side-chain of Cys-83 and the iron-sulfur cluster, a feature not present in other known Rieske oxygenase ferredoxins. 

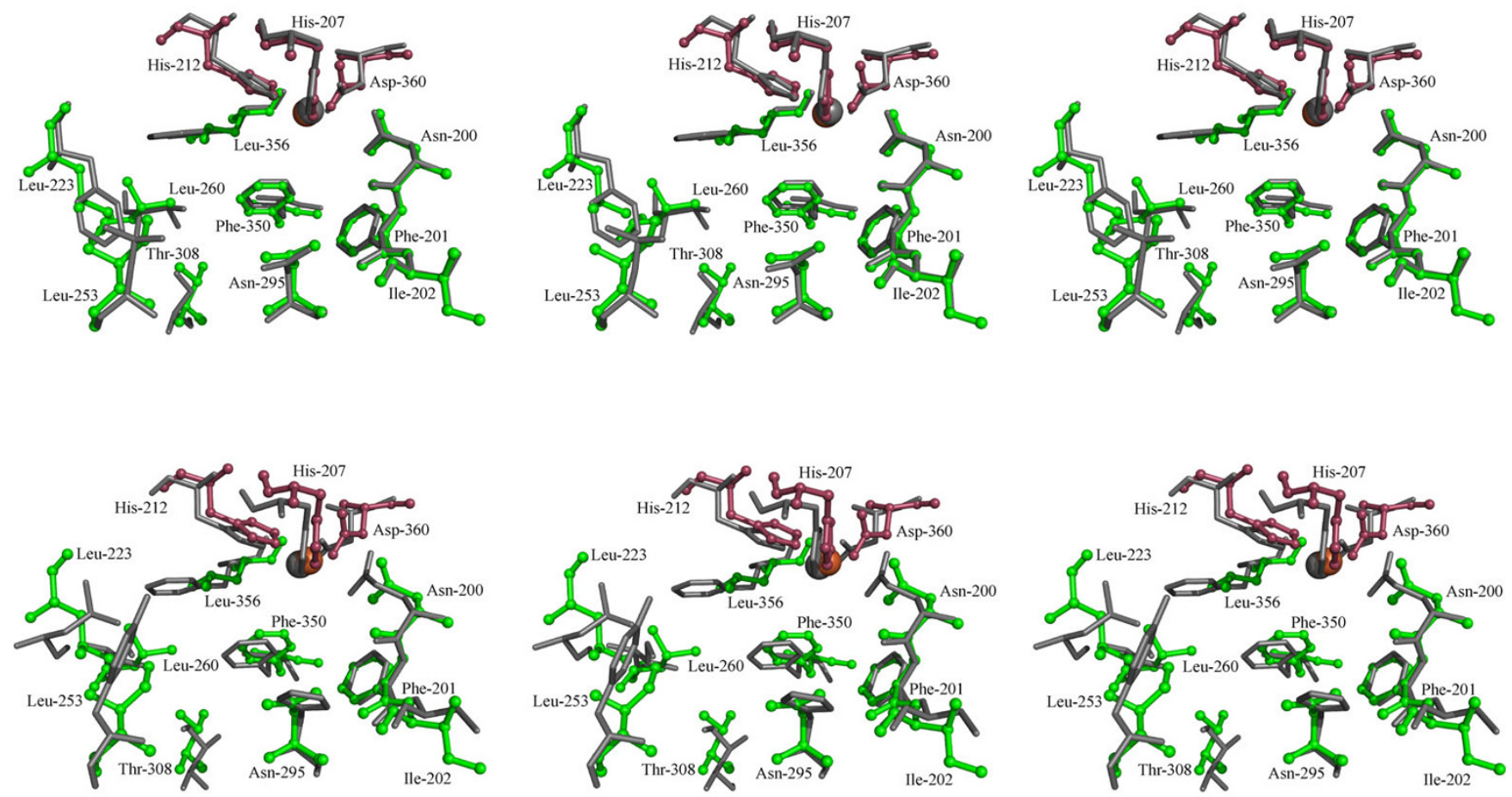

Figure 7

Comparison of biphenyl 2,3-dioxygenase active site to other Rieske oxygenaes. Comparison of the active sites of

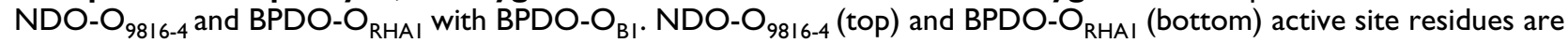
shown as smooth grey lines and the active site iron is shown as a grey sphere. BPDO-O $\mathrm{BI}_{1}$ is aligned and overlaid in each of the images. Residues that coordinate the mononuclear iron are shown as red ball and stick models, while residues that form the active site pocket are shown as green ball and stick models. The mononuclear iron for BPDO- ${ }_{\mathrm{BI}}$ is shown as a rust colored sphere. Residues are labeled using numbering from BPDO- $\mathrm{O}_{\mathrm{BI}}$. Left and center images are wall-eyed stereo, center and right images are cross-eyed stereo.

mations were modeled using the molecular visualization programs XtalView [61] and Coot [56]. The calculated solvent content was $50 \%$ [62]. The asymmetric unit contains a complete $\alpha_{3} \beta_{3}$ protein.

Data from biphenyl soaked oxygenase crystals were processed using $\mathrm{d}^{*}$ TREK to a resolution of $2.8 \AA$. The native BPDO-O $\mathrm{B}_{\mathrm{B} 1}$ structure, with solvent molecules removed, was used as a starting point for the refinement of the ligand bound structure. An energy-minimized structure of the small molecule biphenyl was constructed using the program SYBYL 7.1 [63]. This model was used to create a refinement dictionary for Refmac5 using the ligand sketcher program in CCP4-5.0.2. After initial refinement of the protein model, the biphenyl ligand was modeled into the active site of the enzyme where electron density maps showed un-modeled density in both 2Fo-Fc and FoFc maps. The torsion angle between the two rings of biphenyl was allowed to rotate during refinement and solvent molecules were modeled as appropriate.

\section{Sequence and structural alignments}

TCoffee [64] was used to produce a structure-based sequence alignment of the four known RO ferredoxin structures and 19 other RO ferredoxin sequences. Structural alignment of native $\mathrm{BPDO}-\mathrm{O}_{\mathrm{B} 1}$ with structures of other RO oxygenases was performed using the program Indonesia [65]. Structural alignments in Indonesia were done pairwise using the Levitt and Gerstein method with a cut-off value of $3.5 \AA$. Sequence alignment and comparison was done using full sequences for each of the proteins without structural information. Protein-protein sequence alignments were performed using blastp on the NCBI blast server [66]. All figures showing structures were created using PyMOL 0.98 [67]. Figure 6 was produced using a modified version of LigPlot [68]. 


\section{Abbreviations}

RO - Rieske Oxygenase

BPDO-O $\mathrm{B}_{\mathrm{B} 1}$ - Biphenyl 2,3-dioxygenase from Sphingobium yanoikuyae strain B1

BPDO-F $\mathrm{B}_{\mathrm{B} 1}$ - Biphenyl 2,3-dioxygenase ferredoxin from Sphingobium yanoikuyae strain B1

BPDO-O RHA1 $_{-}$Biphenyl 2,3-dioxygenase from Rhodococcus sp. strain RHA1
NDO- $\mathrm{F}_{9816-4}$ - Naphthalene 1,2-dioxygenase ferredoxin from Pseudomonas sp. strain NCIB 9816-4

NDO-O ${ }_{9816-4}$ - Naphthalene 1,2-dioxygenase from Pseudomonas sp. strain NCIB 9816-4

B1 - Sphingobium yanoikuyae strain B1

\section{Authors' contributions}

D.J.F. generated the biphenyl-bound oxygenase crystals and carried out the structural work with the oxygenase component. E.N.B. carried out work on the ferredoxin component. D.J.F. and E.N.B. contributed equally to the

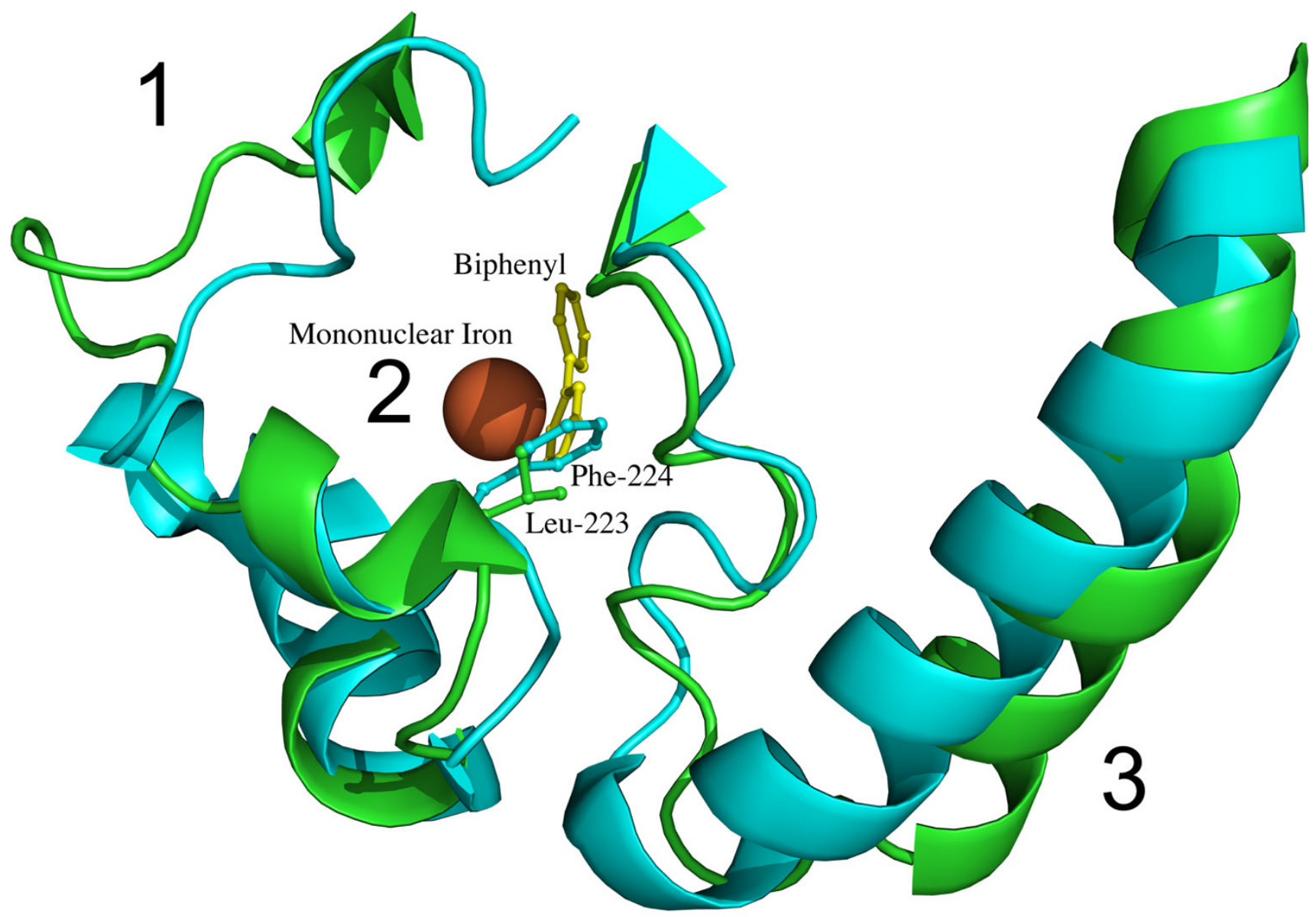

Figure 8

Comparison of the active site entrances of BPDO-O $\mathbf{B}_{\mathrm{B}}$ and $\mathbf{N D O}-\mathbf{O}_{\mathbf{9 8 1 6 - 4}}$. Cartoon diagrams of the active site entrances for BPDO-O $\mathrm{B}_{\mathrm{BI}}$ (green) and NDO-O $\mathrm{O}_{9816-4}$ (cyan). Multiple differences in the loop structure lead to a larger opening to the active site in BPDO-O $\mathrm{B}_{\mathrm{B}}$. At position I, the loop structure is pushed away from the entrance, compared to NDO-O $9816-4$. Position 2 shows the increased bulk of the Phe-224 side chain in the entrance opening, compared to the side chain of Leu-223 of BPDO-O $\mathrm{BI}_{\mathrm{B}}$. Finally, postion 3 shows a shift of the helix, which pulls the active site entrance open, compared to NDO-O ${ }_{9816-}$ 4. Biphenyl bound in the active site is shown in yellow and the mononuclear iron is shown as a rust-colored sphere. See Additional file I, which shows these structures rotating in three dimensional space. 
drafting of this manuscript. C.-L. Y. expressed, purified and crystallized both the ferredoxin and oxygenase components. R.E.P. and D.T.G. conceived of the studies and gave guidance. S.R. was involved in planning X-ray crystallographic experiments and the interpretation of results. All authors have read and approved the manuscript.

\section{Additional material}

\section{Additional File 1}

Comparison of the active site entrances of BPDO-OB1 and NDOO9816-4. Animation of cartoon diagrams of the active site entrances for $B P D O-O_{B 1}$ (green) and $\mathrm{NDO}-\mathrm{O}_{9816-4}$ (cyan). Multiple differences in the loop structure lead to a larger opening to the active site in $B P D O-O_{B 1}$. Biphenyl bound in the active site is shown in yellow and the mononuclear iron is shown as a rust-colored sphere. Phe-224 (NDO-O $9816-4)$ and Leu$223\left(B P D O-O_{B 1}\right)$ are shown with side chains as ball and stick models. Click here for file

[http://www.biomedcentral.com/content/supplementary/14726807-7-10-S1.mov]

\section{Acknowledgements}

We thank Jon Mowers, Adam Okerlund, Nathan Coussens and Heather Hanson for critical reading of this manuscript and assistance with various experiments performed in this manuscript. We also thank Gerben Zylstra for providing clones of the BIbphA IA2f genes. Use of the IMCA-CAT beamline I7-ID at the Advanced Photon Source was supported by the companies of the Industrial Macromolecular Crystallography Association through a contract with the Center for Advanced Radiation Sources at the University of Chicago. Use of the Advanced Photon Source was supported by the U. S. Department of Energy, Office of Science, Office of Basic Energy Sciences, under Contract No. W-3I-109-Eng-38. We would like to thank Lisa Keefe, Kevin Battaile and Irina Koshelev for help with data collection at the IMCA-CAT facility. Research carried out at X6A beam line, National Synchrotron Light Source, Brookhaven National Laboratory, is supported by the U.S. Department of Energy under contract \# DE-AC02-98CHI 0886 $\mathrm{X} 6 \mathrm{~A}$ is funded by NIH/NIGMS under agreement $\mathrm{YI}$ GM-0080-03. We thank Vivian Stojanoff for help with data collection at X6A. D.F. and E.B. are $U$. of I. MSTP trainees and would like to acknowledge financial support through a fellowship from the U. of I. Center for Biocatalysis and Bioprocessing. D.F. would like to acknowledge a thesis-parts award by the Department of Energy Division of Student Programs for work at the Advanced Photon Source in Argonne National Laboratory. C.-L.Y would like to acknowledge financial support by National Science Foundation Engineering Research Centers Program grant \# EEC-03 10689. S.R. would like to acknowledge financial support from USPHS Grant \# GM62904.

\section{References}

I. Khan AA, Wang RF, Cao WW, Franklin W, Cerniglia CE: Reclassification of a polycyclic aromatic hydrocarbon-metabolizing bacterium, Beijerinckia sp. strain BI, as Sphingomonas yanoikuyae by fatty acid analysis, protein pattern analysis, DNA-DNA hybridization, and 165 ribosomal DNA sequencing. Int J Syst Bacteriol 1996, 46(2):466-469.

2. Gibson DT, Roberts RL, Wells MC, Kobal VM: Oxidation of biphenyl by a Beijerinckia species. Biochem Biophys Res Commun 1973 , 50(2):2II-2I9.

3. Gibson DT: Beijerinckia sp strain BI: a strain by any other name. J Ind Microbiol Biotechnol 1999, 23(4-5):284-293.
4. Kim SJ, Kweon O, Freeman JP, Jones RC, Adjei MD, Jhoo JW Edmondson RD, Cerniglia CE: Molecular cloning and expression of genes encoding a novel dioxygenase involved in low- and high-molecular-weight polycyclic aromatic hydrocarbon degradation in Mycobacterium vanbaalenii PYR-I. Appl Environ Microbiol 2006, 72(2): 1045-1054.

5. Jouanneau Y, Meyer C: Purification and characterization of an arene cis-dihydrodiol dehydrogenase endowed with broad substrate specificity toward polycyclic aromatic hydrocarbon dihydrodiols. Appl Environ Microbiol 2006, 72(7):4726-4734.

6. Demaneche S, Meyer C, Micoud J, Louwagie M, Willison JC, Jouanneau $Y$ : Identification and functional analysis of two aromaticring-hydroxylating dioxygenases from a Sphingomonas strain that degrades various polycyclic aromatic hydrocarbons. Appl Environ Microbiol 2004, 70(I I ):67I 4-6725.

7. Jouanneau Y, Meyer C, Jakoncic J, Stojanoff V, Gaillard J: Characterization of a naphthalene dioxygenase endowed with an exceptionally broad substrate specificity toward polycyclic aromatic hydrocarbons. Biochemistry 2006, 45(40): I 2380-12391.

8. Gibson DT, Mahadevan V, Jerina DM, Yogi H, Yeh HJ: Oxidation of the carcinogens benzo[ $a]$ pyrene and benzo[a] anthracene to dihydrodiols by a bacterium. Science 1975, 1 89(4199):295-297.

9. Zylstra GJ, Kim E: Aromatic hydrocarbon degradation by Sphingomonas yanoikuyae BI. J Ind Microbiol Biotechnol 1997, 19(5-6):408-414.

10. Kim E, Zylstra G]: Functional analysis of genes involved in biphenyl, naphthalene, phenanthrene, and $m$-xylene degradation by Sphingomonas yanoikuyae B I. J Ind Microbiol Biotechnol 1999, 23(4-5):294-302.

II. Yu CL, Liu W, Ferraro DJ, Brown EN, Ramaswamy S, Parales RE, Gibson DT: Purification, characterization, and crystallization of the components of a biphenyl dioxygenase system from Sphingobium yanoikuyae BI. J Ind Microbiol Biotechnol 2007, 34(4):3II-24

12. Cho O, Choi KY, Zylstra GJ, Kim YS, Kim SK, Lee JH, Sohn HY, Kwon GS, Kim YM, Kim E: Catabolic role of a three-component salicylate oxygenase from Sphingomonas yanoikuyae BI in polycyclic aromatic hydrocarbon degradation. Biochem Biophys Res Commun 2005, 327(3):656-662.

13. Bae M, Kim E: Association of a common reductase with multiple aromatic terminal dioxygenases in Sphingomonas yanoikuyae strain BI. J Microbiol 2000, 38:40-43.

14. Moritz E, Ni' Chadhain SM, Kim E, Zylstra GJ: Cloning, sequencing, and characterization of a multicomponent biphenyl dioxygenase system from Sphingomonas yanoikuyae B I: Abstract. 104th General Meeting of the American Society for Microbiology, New Orleans, LA 2004.

15. Dong X, Fushinobu S, Fukuda E, Terada T, Nakamura S, Shimizu K, Nojiri $H$, Omori T, Shoun H, Wakagi T: Crystal structure of the terminal oxygenase component of cumene dioxygenase from Pseudomonas fluorescens IP0I. J Bacteriol 2005, I 87(7):2483-2490

16. Furusawa $Y$, Nagarajan $V$, Tanokura M, Masai E, Fukuda M, Senda $T$ Crystal structure of the terminal oxygenase component of biphenyl dioxygenase derived from Rhodococcus sp. strain RHAI. Mol Biol 2004, 342(3): I 04 I- 1052

17. Imbeault NY, Powlowski JB, Colbert CL, Bolin JT, Eltis LD: Steadystate kinetic characterization and crystallization of a polychlorinated biphenyl-transforming dioxygenase. I Biol Chem 2000, 275( (17): 12430-I2437.

18. Zielinski M, Kahl S, Hecht HJ, Hofer B: Pinpointing biphenyl dioxygenase residues that are crucial for substrate interaction. $J$ Bacteriol 2003, 185(23):6976-6980.

19. Furukawa K: Engineering dioxygenases for efficient degradation of environmental pollutants. Curr Opin Biotechnol 2000, I I(3):244-249.

20. Furukawa $\mathrm{K}$, Suenaga $\mathrm{H}$, Goto $\mathrm{M}$ : Biphenyl dioxygenases: functional versatilities and directed evolution. I Bacteriol 2004, 186(16):5|89-5196.

2I. Brenner V, Arensdorf J], Focht DD: Genetic construction of PCB degraders. Biodegradation 1994, 5(3-4):359-377.

22. Pieper DH: Aerobic degradation of polychlorinated biphenyls. Appl Microbiol Biotechnol 2005, 67(2): I70-191.

23. Ferraro DJ, Gakhar L, Ramaswamy S: Rieske business: Structurefunction of Rieske non-heme oxygenases. Biochem Biophys Res Commun 2005, 338(1): 175-190. 
24. Lee K: Involvement of electrostatic interactions between the components of toluene dioxygenase from Pseudomonas putida FI. J Microbiol Biotechnol 1998, 8(4):4I6-42I.

25. Kabsch W: A solution for the best rotation to relate two sets of vectors. Acta Crystallogr A 1976, 32(5):922-923.

26. Gakhar L, Malik ZA, Allen CC, Lipscomb DA, Larkin MJ, Ramaswamy S: Structure and increased thermostability of Rhodococcus sp. naphthalene I,2-dioxygenase. J Bacteriol 2005, |87(2I):7222-7231.

27. Karlsson A, Parales JV, Parales RE, Gibson DT, Eklund H, Ramaswamy $S$ : Crystal structure of naphthalene dioxygenase: side-on binding of dioxygen to iron. Science 2003, 299(5609): I039- 042

28. Kauppi B, Lee K, Carredano E, Parales RE, Gibson DT, Eklund H, Ramaswamy S: Structure of an aromatic-ring-hydroxylating dioxygenase-naphthalene I,2-dioxygenase. Structure 1998, 6(5):57I-586

29. Nojiri H, Ashikawa $Y$, Noguchi H, Nam JW, Urata M, Fujimoto Z, Uchimura H, Terada T, Nakamura S, Shimizu K, Yoshida T, Habe H, Omori T: Structure of the terminal oxygenase component of angular dioxygenase, carbazole 1,9a-dioxygenase. I Mol Biol 2005, 35 I(2):355-370.

30. Martins BM, Svetlitchnaia T, Dobbek H: 2-Oxoquinoline 8monooxygenase oxygenase component: active site modulation by Rieske-[2Fe-2S] center oxidation/reduction. Structure 2005, I 3(5):8I 7-824.

31. Murzin AG, Brenner SE, Hubbard T, Chothia C: SCOP: a structura classification of proteins database for the investigation of sequences and structures. J Mol Biol 1995, 247(4):536-540.

32. Wolfe MD, Altier DJ, Stubna A, Popescu CV, Munck E, Lipscomb JD: Benzoate I,2-dioxygenase from Pseudomonas putida: single turnover kinetics and regulation of a two-component Rieske dioxygenase. Biochemistry 2002, 4 I(30):96I I-9626.

33. Wolfe MD, Lipscomb JD: Hydrogen peroxide-coupled cis-diol formation catalyzed by naphthalene 1,2-dioxygenase. I Biol Chem 2003, 278(2):829-835.

34. Wolfe MD, Parales J, Lee K, Gibson DT, Lipscomb JD: Substrate binding to the mononuclear ferrous ion of the Rieske dioxygenase naphthalene 1,2-dioxygenase from Pseudomonas sp NCIB 98 I 6-4. J Inorg Biochem I999, 74( I-4):339.

35. Wolfe MD, Parales JV, Gibson DT, Lipscomb JD: Single turnover chemistry and regulation of $\mathrm{O} 2$ activation by the oxygenase component of naphthalene I,2-dioxygenase. J Biol Chem 200I, 276(3): 1945-1953.

36. Yang TC, Wolfe MD, Neibergall MB, Mekmouche Y, Lipscomb JD, Hoffman BM: Modulation of substrate binding to naphthalene I,2-dioxygenase by Rieske cluster reduction/oxidation. J Am Chem Soc 2003, I 25(8):2034-2035

37. Yang TC, Wolfe MD, Neibergall MB, Mekmouche Y, Lipscomb JD, Hoffman BM: Substrate binding to NO-ferro-naphthalene I,2dioxygenase studied by high-resolution $\mathbf{Q}$-band pulsed $\mathbf{2} \mathbf{H}$ ENDOR spectroscopy. J Am Chem Soc 2003, I 25(23):7056-7066.

38. Karlsson A: Structural and mechanistic studies of Rieske dioxygenases. Department of Molecular Biology. Uppsala, Sweden, The Swedish University of Agricultural Sciences 2002

39. Karlsson A, Parales JV, Parales RE, Gibson DT, Eklund H, Ramaswamy S: NO binding to naphthalene dioxygenase. J Biol Inorg Chem 2005.

40. Carredano E, Karlsson A, Kauppi B, Choudhury D, Parales RE, Parales JV, Lee K, Gibson DT, Eklund H, Ramaswamy S: Substrate binding site of naphthalene I,2-dioxygenase: functional implications of indole binding. J Mol Biol 2000, 296(2):70I-7I2.

4I. Friemann R: Structure-function studies of iron sulfur enzyme systems. Department of Molecular Biology. Uppsala, Sweden, The Swedish University of Agricultural Sciences 2005.

42. Friemann R, Ivkovic-Jensen MM, Lessner DJ, Yu CL, Gibson DT, Parales RE, Eklund H, Ramaswamy S: Structural insight into the dioxygenation of nitroarene compounds: the crystal structure of nitrobenzene dioxygenase. I Mol Biol 2005 348(5): I|39-|| $5 \mid$.

43. Parales RE: The role of active-site residues in naphthalene dioxygenase. J Ind Microbiol Biotechnol 2003, 30(5):27I-278.

44. Ziffer H, Jerina DM, Gibson DT, Kobal VM: Absolute stereochemistry of the (+)-cis-I,2-dihydroxy-3-methylcyclohexa-3,5diene produced from toluene by Pseudomonas putida. J Am Chem Soc 1 973, 95( 1 2):4048-4049.
45. Ferraro DJ, Okerlund AL, Mowers JC, Ramaswamy S: Structural basis for regioselectivity and stereoselectivity of product formation by naphthalene I,2-dioxygenase. J Bacteriol 2006 , I 88( I9):6986-6994.

46. Colbert CL, Couture MM, Eltis LD, Bolin JT: A cluster exposed: structure of the Rieske ferredoxin from biphenyl dioxygenase and the redox properties of Rieske Fe-S proteins. Structure 2000, 8( I 2): I 267-I278.

47. Iwata S, Saynovits M, Link TA, Michel H: Structure of a water soluble fragment of the 'Rieske' iron-sulfur protein of the bovine heart mitochondrial cytochrome bcl complex determined by MAD phasing at I.5 A resolution. Structure 1996, 4(5):567-579.

48. Nam JW, Noguchi H, Fujimoto Z, Mizuno H, Ashikawa Y, Abo M, Fushinobu S, Kobashi N, Wakagi T, Iwata K, Yoshida T, Habe H, Yamane $\mathrm{H}$, Omori T, Nojiri H: Crystal structure of the ferredoxin component of carbazole I,9a-dioxygenase of Pseudomonas resinovorans strain CA I 0, a novel Rieske non-heme iron oxygenase system. Proteins 2005, 58(4):779-789.

49. Skjeldal L, Peterson FC, Doreleijers JF, Moe LA, Pikus JD, Westler WM, Markley JL, Volkman BF, Fox BG: Solution structure of T4moC, the Rieske ferredoxin component of the toluene 4monooxygenase complex. I Biol Inorg Chem 2004, 9(8):945-953.

50. Parales RE, Lee K, Resnick SM, Jiang H, Lessner DJ, Gibson DT: Substrate specificity of naphthalene dioxygenase: effect of specific amino acids at the active site of the enzyme. I Bacteriol 2000, I 82(6): | 64 I- I649.

5I. Mahaffey WR, Gibson DT, Cerniglia CE: Bacterial oxidation of chemical carcinogens: formation of polycyclic aromatic acids from benz[a]anthracene. Appl Environ Microbiol 1988, 54( I 0):24I5-2423

52. Pflugrath JW: The finer things in $\mathbf{X}$-ray diffraction data collection. Acta Crystallogr D Biol Crystallogr 1999, 55(Pt I0): I7I8-I725.

53. Navaza J: AMoRe: an automated package for molecular replacement. Acta Crystallogr A 1994, 50:I57- I63.

54. Jones TA, Zou JY, Cowan SW, Kjeldgaard: Improved methods for building protein models in electron density maps and the location of errors in these models. Acta Crystallogr A I 991, 47(Pt 2): I10-119.

55. Emsley P, Cowtan K: Coot: model-building tools for molecular graphics. Acta Crystallogr D Biol Crystallogr 2004, 60(Pt 12 Pt I):2126-2132

56. Murshudov GN, Vagin AA, Dodson EJ: Refinement of macromolecular structures by the maximum- likelihood method. Acto Crystallogr D Biol Crystallogr 1997, 53:240-255.

57. Perrakis A, Sixma TK, Wilson KS, Lamzin VS: wARP: improvement and extension of crystallographic phases by weighted averaging of multiple-refined dummy atomic models. Acta Crystallogr D Biol Crystallogr 1997, 53(Pt 4):448-455.

58. Lamzin VS, Wilson KS: Automated refinement of protein models. Acta Crystallogr D Biol Crystallogr 1993, 49(Pt I): 129-|47.

59. The CCP4 suite: programs for protein crystallography. Acta Crystallogr D Biol Crystallogr 1994, 50(Pt 5):760-763.

60. McRee DE: A visual protein crystallographic software system for XI I/XView. J Mol Graphics 1992, I 0:44-46.

6I. Matthews BW: Solvent content of protein crystals. I Mol Biol |968, 33:49|-497.

62. SYBYL. Version 7.I. St. Louis, MO, Tripos, Inc.

63. Poirot O, O'Toole E, Notredame C: Tcoffee@igs: A web server for computing, evaluating and combining multiple sequence alignments. Nucleic Acids Res 2003, 3 I ( I 3):3503-3506.

64. Madsen D, Johansson P, Kleywegt GJ: Indonesia. Version I.4. Uppsala, Sweden , Uppsala Software Factory; 2002:An integrated sequence analysis program.

65. Altschul SF, Madden TL, Schaffer AA, Zhang J, Zhang Z, Miller W, Lipman DJ: Gapped BLAST and PSI-BLAST: a new generation of protein database search programs. Nucleic Acids Res 1997, 25( I 7):3389-3402

66. DeLano WL: The PyMOL Molecular Graphics System. Version 0.98. San Carlos, CA, USA, DeLano Scientific; 2000.

67. Wallace AC, Laskowski RA, Thornton JM: LIGPLOT: a program to generate schematic diagrams of protein-ligand interactions. Protein Eng 1995, 8(2): |27-|34. 